\title{
Treatment of Fractures in Black Africa: The Current State of Play
}

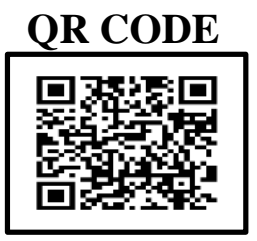

\section{Dr. Packo Dieu-le-veut Saint-Cyr Sylvestre ${ }^{1,2}$ and Dr. Feigoudozoui Hermann Victoire}

Africa is a continent where the cases of trauma are most frequent. These trauma are mostly due to road accidents. ${ }^{1}$ Underdevelopment observed in Africa, indirectly favors poor quality of health department with an under-equipped health structure. Consequently, the condition of management of patient is insufficient in the orthopedic-traumatology departments. That's why, the results of the treatment are sometimes mediocre. Even though we know that the treatment of fractures is either orthopedic or surgical, in both cases, the good quality of the technical platform and the department are necessary for an excellent result. Now a days, several progress has being made concerning the management of fractures. $^{2}$ However, these advances are not yet fully integrated into the Africa's health's departments. The Maghreb countries are already experiencing a clear improvement in their technical platforms.

Global epidemiological data for fractures are not available. However, only some countries have this data. The finding is that the incidence of fractures is higher in Africa. The purpose of this comment is to recall the difficulties of the practice of orthopedic and traumatological surgery in sub-Saharan Africa.

\section{CIRCUMSTANCE OF FRACTURES}

In Africa, the circumstances of trauma are dominated by road accidents. ${ }^{3}$ This is due to the poor condition of the roads and the non respect of the rules of the road by the drivers and the pedestrians. The other circumstance of trauma in Africa is represented by weapon aggression. Armed attacks are recent and rising in recent conflicts.

\section{WORKING CONDITIONS}

The working conditions of the trauma orthopedic surgeon in Africa remain poor. The operating room is under-equipped. Hygiene is not always mandatory in all departments. Some operating rooms suffer from a lack of permanent electricity.

\section{THE TECHNICAL PLATFORM}

The majority of operating rooms do not have materials of work. Recent innovative implants in trauma surgery are not available in all health facilities in Africa. In the Central African Republic, for example, Küntcher's nail is still used today for intramedullary nailing. ${ }^{4}$ The mechanical complications of osteosynthesis are therefore frequent. Laparoscopy exists only in a few countries in Sub-Saharan Africa. Surgery boxes often have old instruments. The renewal and maintenance of medical devices are not regularly carried out due to lack of financial resources.

\section{HUMAN RESSOURCES}

The number of trauma orthopedic surgeons in subSaharan Africa is significantly insufficient. The typical example is that of the Central African Republic which has only one trauma orthopedic surgeon for a population of 5 million. This is often the result of lack of funding for training. The ratio projected by WHO is not always respected.

\section{TREATMENT RESULTS}

Paradoxically, with a limited technical platform, the results of treatment of fractures in Africa are often good. The medical practitioners often find little tips to produce good results. However, fracture management in sub-Saharan Africa faces a few limitations. The results of the treatment are sometimes influenced by the low purchasing power on the part of the patients. Also, the neglect of charging instructions by some patients sometimes makes the result of some treatments bad, but in a small proportion.

\section{PROSPECT}

Much effort remains to be deployed in the field of orthopedic and traumatological surgery in subSaharan Africa. The training of specialists should be encouraged, strengthened and financed so that the 
departments need to be created. The renewal of instrument boxes is to be applied on a regular basis and to adapt to recent progress. Finally, the image intensifiers, the new implants and their ancillaries as well as the laparoscopic devices must be placed in all departments to improve the quality of the results of the montages.

\section{CONCLUSION}

This work suggests a less positive view of the practice of orthopedic and traumatic surgery in Black Africa. The current context does not facilitate the achievement of good results. It is therefore necessary to improve some aspects in order to optimize a satisfactory result for the good of the patients.

\section{REFERENCES}

1. Ndayisaba G, Bazira L, Rurangwa E. Etude retrospective de l'utilisation et des résultats de l'ostéosynthèse des fractures des membres sur une série de 367 cas. Med Afr Noire. 1992 ; 39(8/9) : 57981

2. Irda N, Putineanu D, Tribak K, Libouton X, Barbier $\mathrm{O}$, Van Cauter $\mathrm{M}$, et al. Innovations en chirurgie orthopédique et traumatologie: que retenir de 2015 ? Louvain Med 2016;135(2):81-5.

3. Tekpa BJD, Dégou SR, Issa-mapouka PA, DouiDoumgba A, Yafondo T, Gaudeuille A. Les cals vicieux diaphysaires du fémur chez l'adulte. RCOT. 2017; 103(7):57

4. Tekpa BJD, Doui-Doumgba A, Feigoudozoui HV, Nghario L, Issa-mapouka PA, Nali MN. Epidémiologie et prise en charge des pseudarthroses diaphysaires de jambe à propos de 104 cas traités selon un algorithme précis en milieu précaire. RCOT. 2018; 104:193-7.

\section{Cite this article as:}

Packo DSS, Feigoudozoui HV. Treatment of Fractures in Black Africa: The Current State of Play. Int Healthc Res J. 2019;3(7):219-220. https://doi.org/10.26440/IHRJ/0307.10298 